\title{
STUDY OF DEFLUORIDATION USING BPAC
}

\author{
Dhamankar S. S $\mathbf{S}^{1}$ Rai R. $K^{2}$, Patil U. $S^{3}$ \\ ${ }^{1}$ Assistant Professor, Department of Civil Engineering, Bharati Vidyapeeth College of Engineering, Lavale, Pune, \\ Maharashtra, India \\ ${ }^{2}$ Associate Professor, Department of Civil Engineering, Government College of Engineering, Amravati, Maharashtra, \\ India \\ ${ }^{3}$ Associate Professor, Department of Civil Engineering , Bharati Vidyapeeth College of Engineering, Lavale, Pune, \\ Maharashtra, India
}

\begin{abstract}
Fluorine is one of the most common elements found in the earth's crust. It is an acute toxin and is deemed to be slightly more toxic than even lead. There are two types of water available namely ground water and surface water. Since some of the fluoride compounds in the earth's upper crust are fairly soluble in water, fluoride exists in both surface as well as ground waters. Typically, surface waters have low concentration of fluoride while groundwater may contain high levels of fluoride. The major objective is to study the process of defluoridation of ground water in the vicinity areas of Vidarbha region. The normal range of fluoride as per BIS is 0.5 to $1.5 \mathrm{mg} / \mathrm{L}$. The main aim of the present study is to study the defluoridation using BPAC (Black Plum Activated Carbon). The complete experimental study has been carried out on batch adsorption process.
\end{abstract}

Keywords: Adsorption, BPAC, Defluoridation, Fluoride, Ground water

$* * *$

\section{INTRODUCTION}

The most abundant minerals containing fluorides are fluorspar, cryolite and apatite. Fluoride compounds are estimated to constitute about $0.08 \%$ of the earth's crust and as such, fluorine ranks about 13th among the elements in order of abundance. Fluorine is recognized as one of the most effective agents. Fluorine is the most electronegative of all elements. Fluoride content in drinking water varies around the world depending on the geographical location. It is one of the common constituents of groundwater. The main sources of fluoride for common people are generally food and drinking water.

Fluoride is generally present in drinking water which is necessary for human health, and is typically added to drinking water, if it is less than the permissible values, to reduce tooth decay. If the concentration of fluoride is greater than permissible standard dental fluorosis and skeletal fluorosis may occur on prolonged consumption of high fluoride content water. Fluoride is essential for mineralization of tissues like bone and teeth, leading to developmental alternations of clinical significance.

Adsorption process by activated carbon is found to be suitable than physical or chemical methods in removal of fluoride and has been quite popular in recent years due to its simplicity. Among different methods used for defluoridation of water, adsorption method is relatively simple, economical, and appropriate for drinking water treatment, especially for small communities.

\section{LITERATURE REVIEW}

Gandhi et al. (2012) studied the low cost adsorbents like chalk powder, pineapple peel powder, orange peel powder, horse gram seed powder, red soil, ragi seed powder, multhani mati, concrete. The adsorbent capacity is more at lower concentration compared to higher concentration. Pineapple peel powder and chalk powder were found to be more effective than other materials and the efficiency got is about $86 \%$.

Deshmukh et al. (2009) carried out the batch adsorption studies to assess the suitability of inexpensive adsorbent prepared from agricultural waste, rice husk. The adsorbent was prepared by chemical impregnation method followed by physical activation. The optimum adsorbent dose was found to be $10 \mathrm{~g} / \mathrm{L}$ by varying the dose of adsorbent from 0 to 16 $\mathrm{g} / \mathrm{L}$; equilibrium was achieved in $120 \mathrm{~min}$ for the optimum $\mathrm{pH}$. It has been observed that the optimum adsorption takes place at lower $\mathrm{pH}$ by varying $\mathrm{pH}$ from $2,4,6,8$, and 10 . Maximum fluoride removal was observed to be $75 \%$ at optimum conditions. Freundlich as well as Langmuir isotherms were plotted and constants of isotherms were determined.

Meenakshi and Maheshwari reported that dental fluorosis and skeletal fluorosis is caused due to excessive fluoride intake. The effects of fluoride in drinking water on animals are analogous to those on human beings are also observed. The continuous use of water having high fluoride concentration also adversely affects the crop growth. 


\section{METHODOLOGY}

There were seven samples collected from Yavatmal district. The samples were collected in clean polythene bottles, which were rinsed first with distilled water and then two to three times by the sample water before collecting the same for analysis. All necessary precautions were taken as per the requirement of sampling program so that it does not deteriorate before it reaches the laboratory. Fluoride concentration of samples can be determined using different instruments like fluorometer, calorimeter, spectrophotometer, etc. In the present study, the fluoride ion concentration was determined by fluorometer CL-53 (ELICO, Hyderabad) shown in Fig. 3.1.

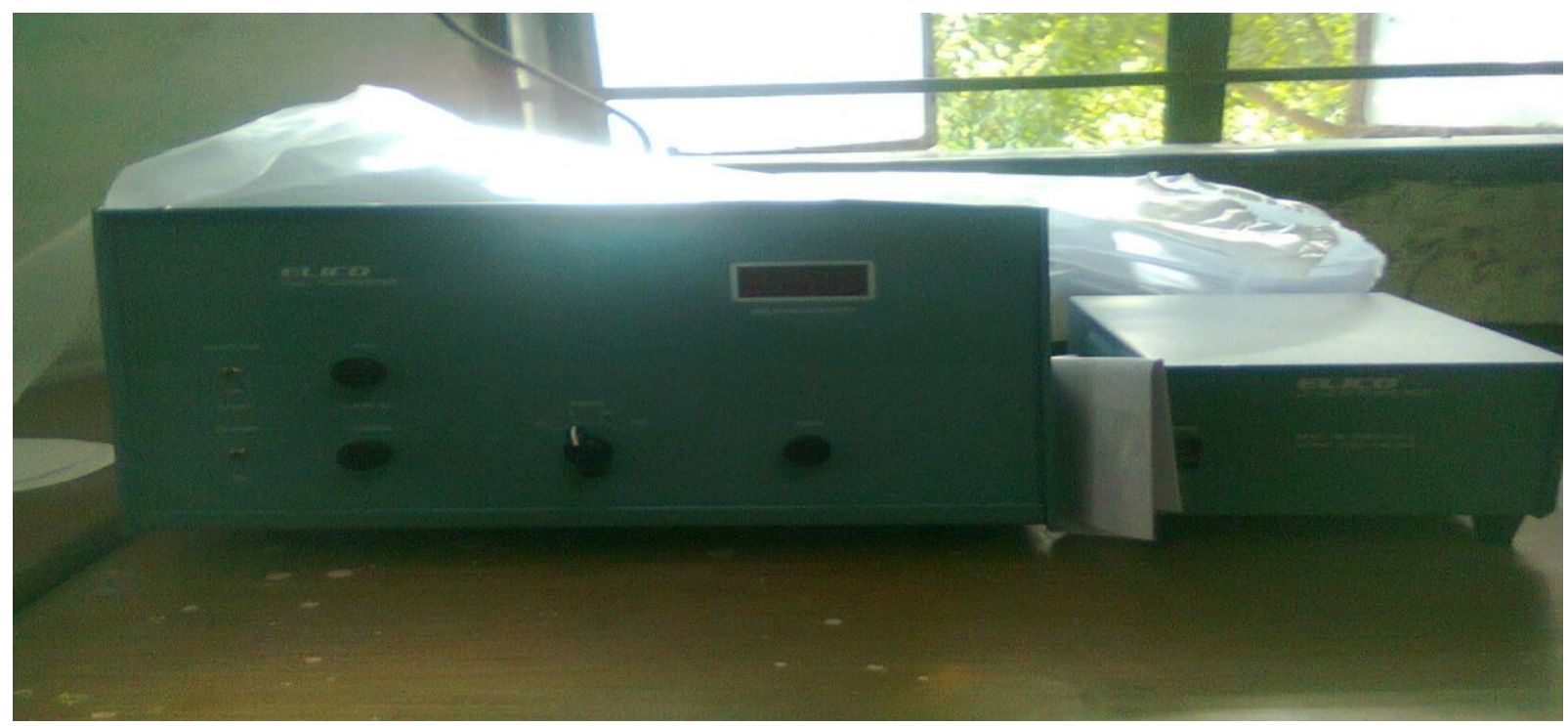

Fig. 3.1: Fluorometer CL-53

Light passes through the media of blank and standard solutions of known concentration and the sample under test in identical conditions. When light energy is incident on a substance, the molecules of the substance in ground state absorb light and transit into excited state. The molecules lose portion of the absorbed energy as vibration energy and return to the ground state emitting some optical energy known as fluorescence. Since portion of the light absorbed is lost in vibration relaxation, the fluorescence emitted by the substance has longer wavelengths than the incident light energy. The intensity of fluorescence emitted is proportional to the optical energy absorbed (Manual).

\section{RESULTS AND DISCUSSION}

The experimental study was carried out in various villages of Yavatmal district. Here, people use ground water for drinking as well as for irrigation purposes. The samples were collected from hand pumps from different sampling stations at village's viz. Konghara, Dharana, Ganeshpur, Wai, Sakhara, Sakhi (Bk), Wadhona. These water samples were collected in clean polyethylene plastic bottles of 100 $\mathrm{ml}$ capacity and before filling, the bottles were rinsed with water under study. The bottles were properly labeled and brought to the laboratory for fluoride determination. A heterogeneous fluoride distribution in range 1.66 to 2.24 $\mathrm{mg} / \mathrm{L}$ were observed in the villages surveyed. Almost all the water sources in these villages showed the evidence of fluoride concentration. The results were obtained using the fluorometer and the values of fluoride concentration in ground water samples are given in Table 4.1. The variation in fluoride concentration for various locations is shown in Fig. 4.1.

Table 4.1: Fluoride Concentration in Villages of Yavatmal District

\begin{tabular}{|l|l|l|}
\hline Villages & Source & Fluoride, $\mathbf{~ m g / L}$ \\
\hline Konghara & HP & 2.00 \\
\hline Dharana & HP & 2.31 \\
\hline Ganeshpur & HP & 1.72 \\
\hline Wai & HP & 2.14 \\
\hline Sakhara & HP & 2.24 \\
\hline Sakhi (Bk) & HP & 1.80 \\
\hline Wadhona & HP & 1.66 \\
\hline
\end{tabular}




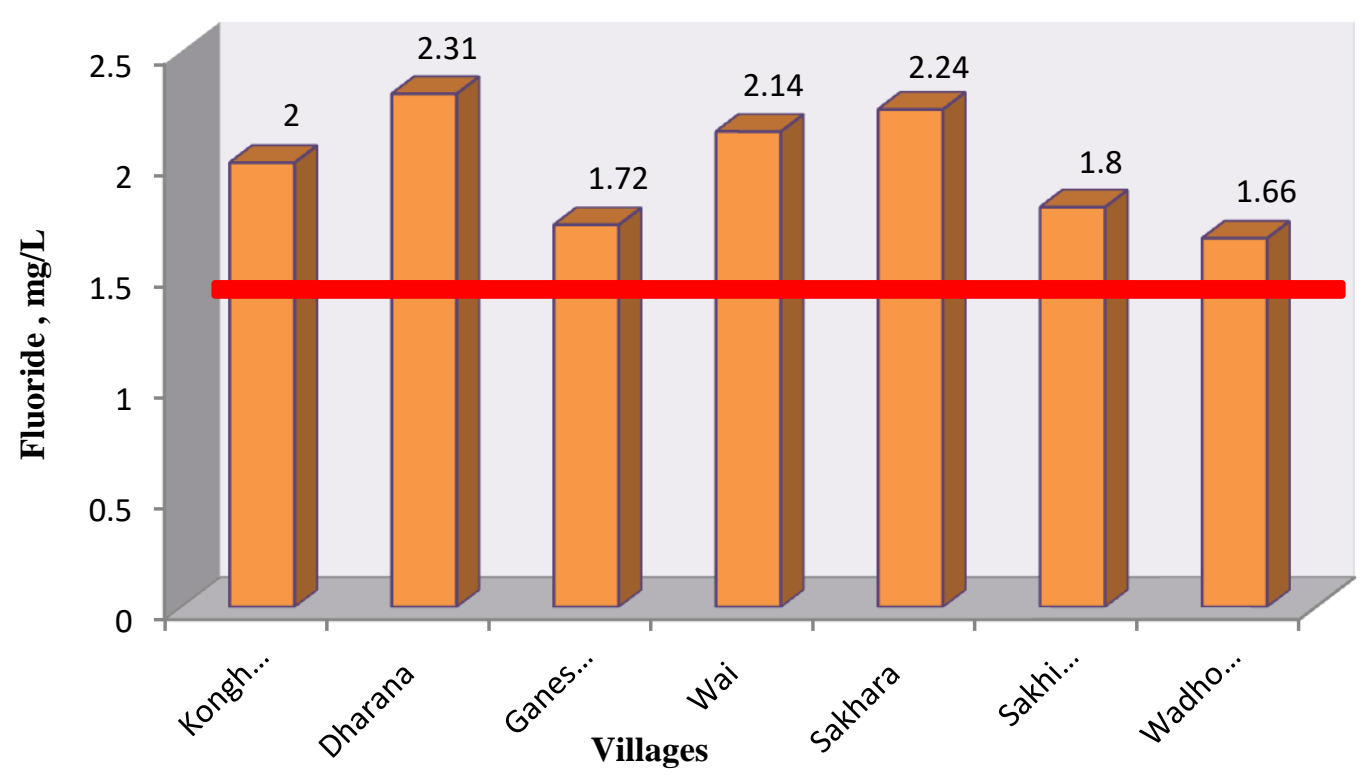

Fig. 4.1: Fluoride Concentration in Villages of Yavatmal District

\subsection{Effect of Dose}

The effect of adsorbent dosage on adsorption of fluoride at $\mathrm{pH} 7$ and contact time of 30 minutes for adsorbent was studied. The results are presented as $\mathrm{C}_{\mathrm{e}}$ on $\mathrm{x}$-axis versus $\mathrm{x} / \mathrm{m}$ on y-axis on a simple graph paper as shown in Fig. 4.1.1.

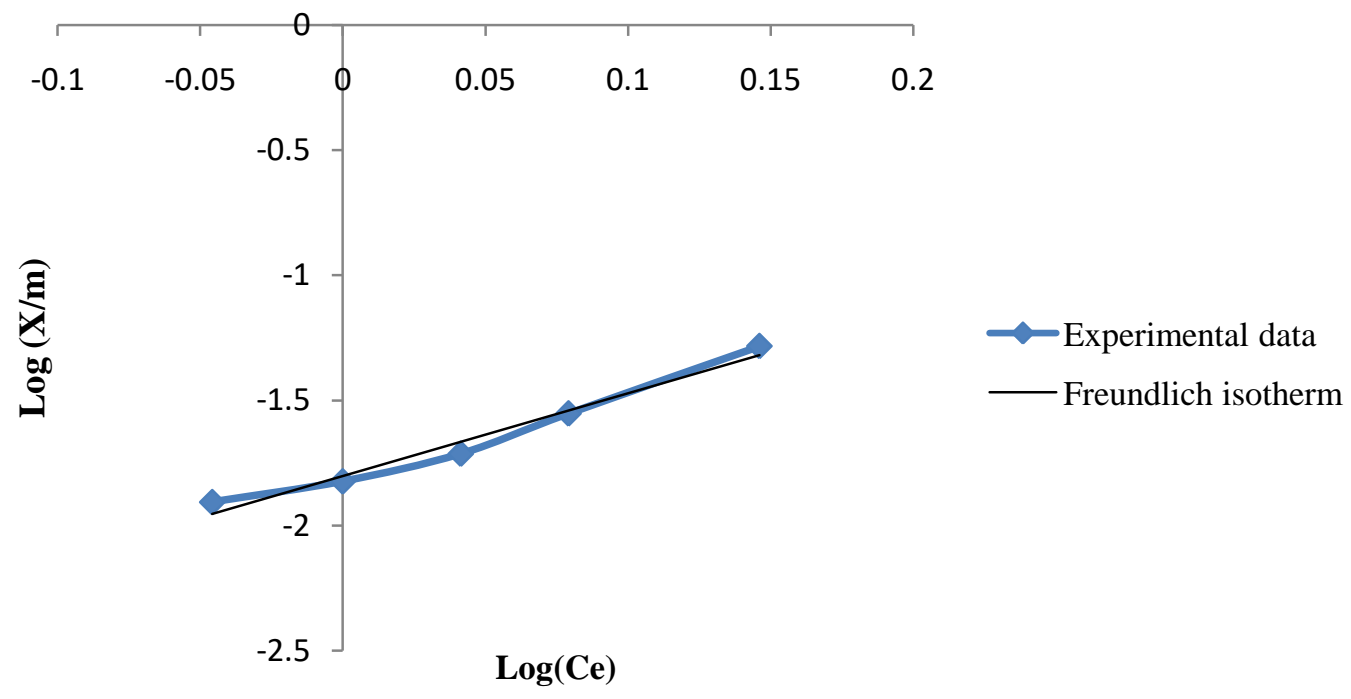

Fig. 4.1.1: Effect of Dose of BPAC on Fluoride Removal

\subsection{Effect of Contact Time}

Fig. 4.2.1 shows the progression of adsorption reaction, the percentage removal of fluoride by BPAC at different contact times. As the contact time increases, initially, the percentage removal also increases. In the present case, the removal time was obtained as 120 minutes for BPAC. The changes in the rate of removal might be due to the fact that initially all the adsorbent sites were vacant and the solute concentration gradient was high. Later, the fluoride uptake rate by adsorbent decreased significantly, due to the decrease in number ofadsorption sites. Decreased removal rate, particularly, towards the end of experiment, indicates the possible monolayer of fluoride ions on the outer surface, pores of both the adsorbents and pore diffusion onto inner surface of adsorbent particles through the film due to continuous shaking and stirring maintained during the experiment. 


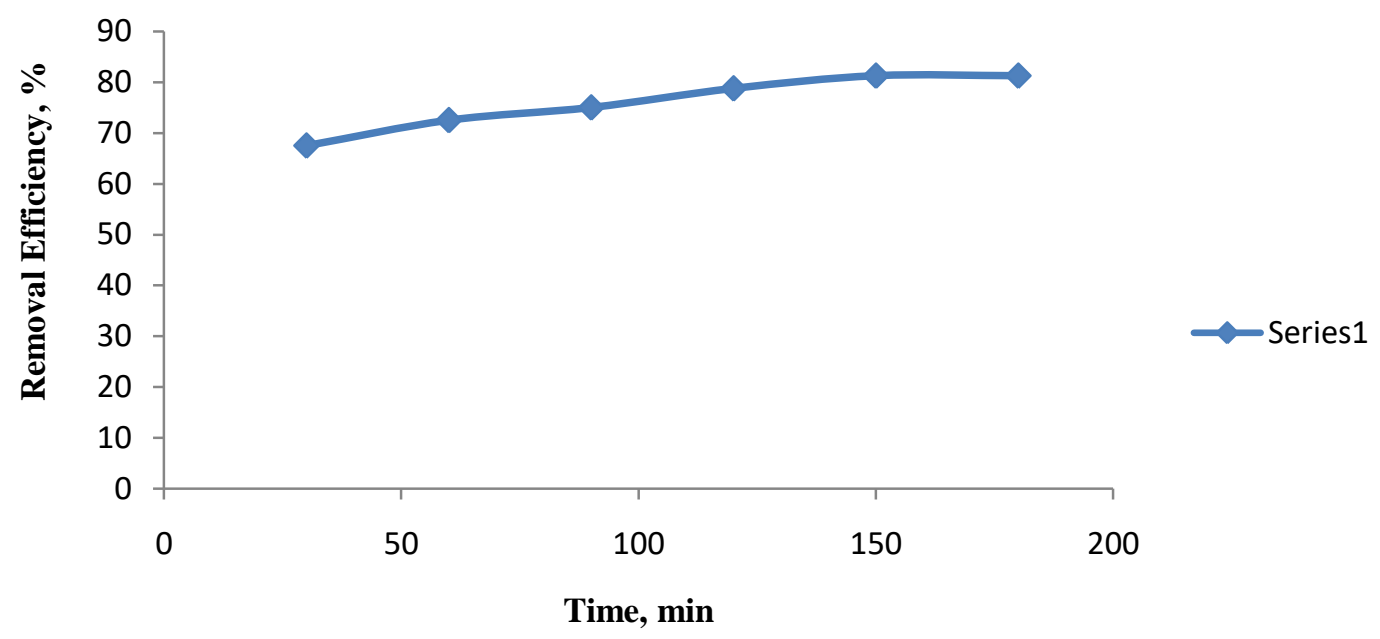

Fig.4.2.1: Effect of Contact Time on Fluoride Removal

\subsection{Effects of Fluoride}

The health risks involved with the higher concentration of fluoride in drinking water is depicted in Figures below. Due to excessive intake, enamel loses its luster. Discoloration may be in the form of spots or horizontal streaks. Skeletal fluorosis affects children as well as adults. Fluoride mainly gets deposited in the joints of neck, knee, pelvic and shoulder bones and makes it difficult to move or walk. The symptoms of skeletal fluorosis are similar to spondylitis or arthritis. Hence, excess or lack of fluoride may lead to dental or skeletal fluorosis, shown in Fig. 4.3.1 and 4.3.2 respectively.

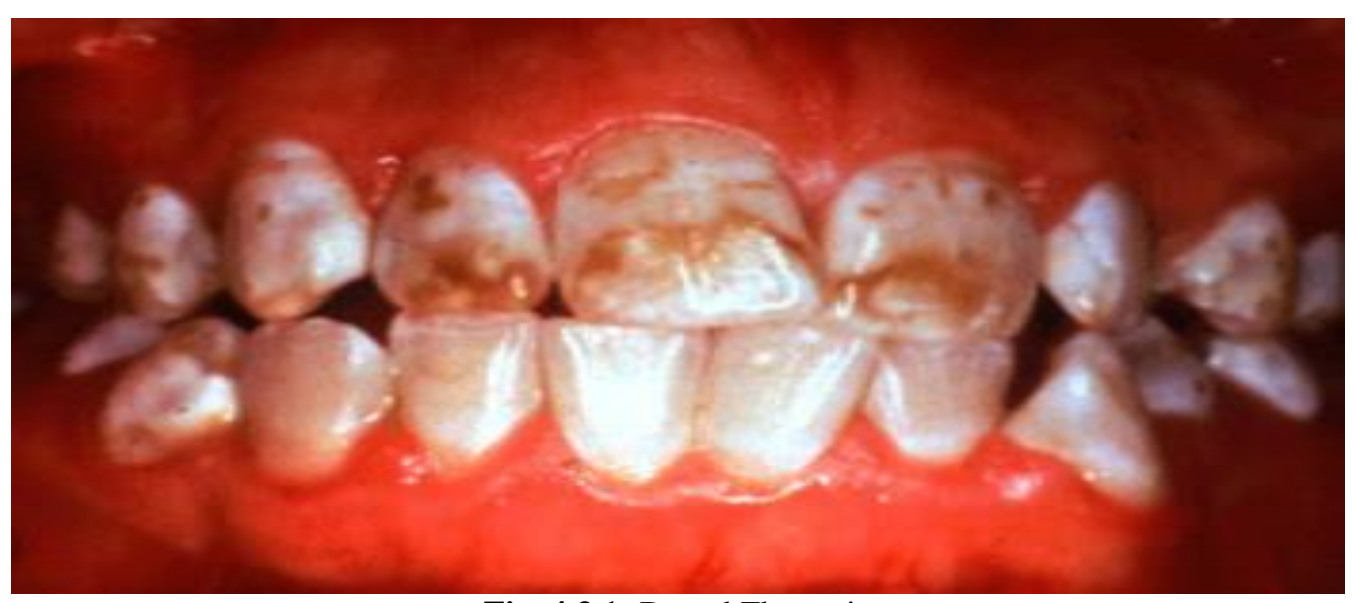

Fig. 4.3.1: Dental Fluorosis

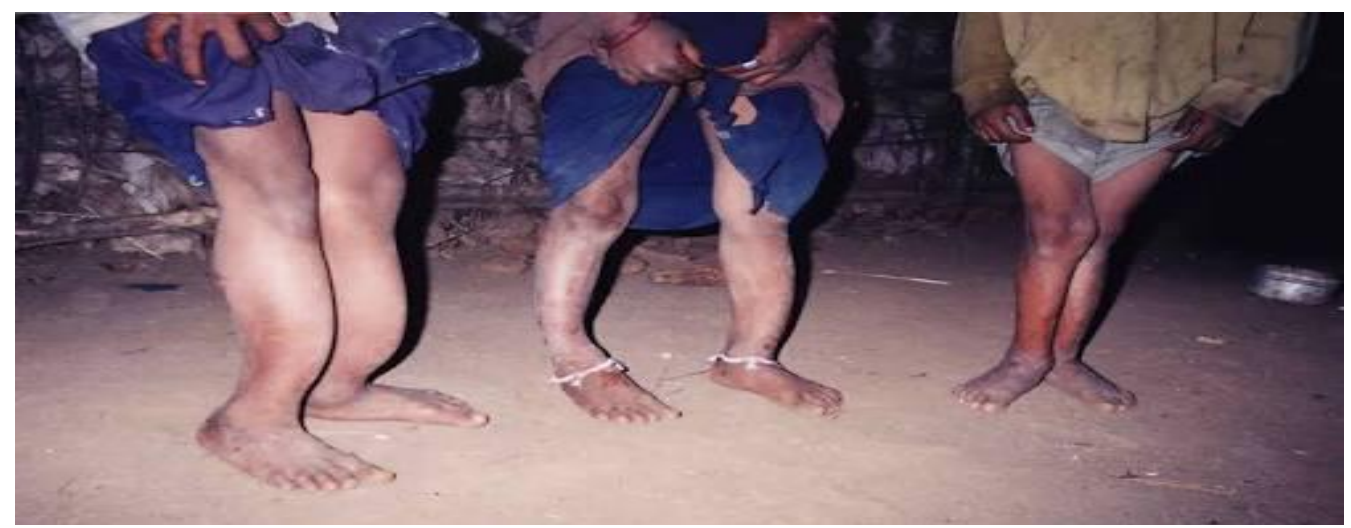

Fig. 4.3.2: Skeletal Fluorosis 


\section{CONCLUSION}

Following conclusions can be drawn from the present experimental study:

$>$ In the present study the fluoride content is greater than the permissible limit in all the seven samples.

$>$ Due to the presence of high fluoride in these samples, there is a need of defluoridation of all the seven water samples.

$>$ It is seen that higher fluoride concentration in the drinking water may lead to health hazards.

$>$ Defluoridation using adsorption process with the help of BPAC is found to be effective.

\section{REFERENCES}

[1] Gandhi, N., Sirisha, D., Chandrashekar, K. B., and Asthana, S. "Removal of fluoride from water and waste water by using low cost adsorbents", International Journal of ChemTech Research, Vol. 4, No. 4, 2012, pp. 1646-1653.

[2] Deshmukh, W. S., Attar, S. J., and Waghmare, M. D. "Investigation of sorption of fluoride in water using rice husk as an adsorbent", Journal on Nature Environment and Pollution Technology, Vol. 8, No. 2, 2009, pp. 217-223.

[3] Rai, R. K., Tingre, A. R., and Nimbalkar, S. S., "Fluoridation and Defluoridation Studies for Groundwater in Ner Taluka", Seminar on Innovation in Construction", CME Pune, $29^{\text {th }}$ and $30^{\text {th }}$ April, 2015.

[4] Brunson, L. R., and Sabatini, D. A. "Role of surface area and surface chemistry during an investigation of Eucalyptus Wood Char for fluoride adsorption from drinking water", Journal of Environmental Engineering, ASCE,2015.

[5] Meenakshi, and Maheshwari, R. C. "Fluoride in drinking water and its removal", Journal of Hazardous Materials, Vol. B 137, 2006, pp. 456-463.

[6] Chavhan, N. K. "Groundwater quality with special reference to fluorosis of Konghara Dharana region, district Yavatmal, Maharashtra, India", International Journal of Science, Environment, Vol. 1, No. 5, 2012, pp. 425-429.

[7] Rai, R. K., Tingre, A. R., and Patil, V. T. "Study on fluoridation and defluoridation of ground waters", International Conference on Sustainable Technology Solutions for Water Management, IWWA, 2015, pp. 343.

[8] User's Manual for Fluorometer CL-53S, ELICO, Hyderabad. 